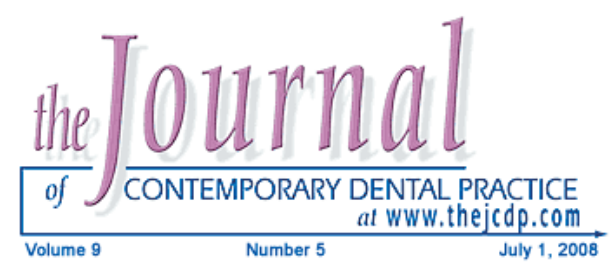

\title{
How to Deal with Esthetically Overcritical Patients Who Need Complete Dentures: A Case Report
}
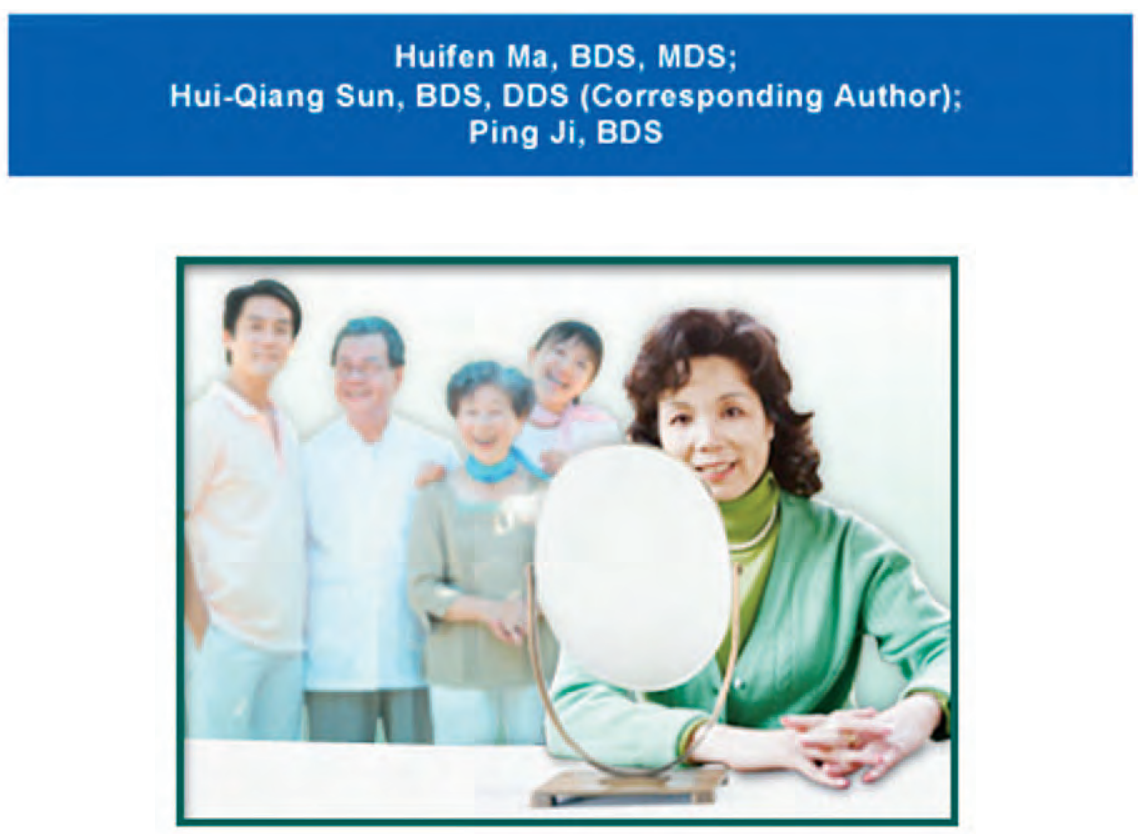

\begin{abstract}
Aim: The purpose of this report is to present a strategy for making a diagnosis and providing appropriate treatment for denture patients with high esthetic demands.

Background: Some edentulous patients have critical requirements for the esthetic aspect of dentures.

Report: A 55-year-old edentulous female presented with a complaint of dissatisfaction with the appearance of two sets of old dentures. A complex method was used during the fabrication of a new set of dentures in order to meet her demand for esthetics.

Summary: This method essentially improves the mutual communication and cooperation between dentists and patients; therefore, it improves satisfaction of the patients.

Keywords: Complete denture, esthetics, psychology, patient satisfaction

Citation: Ma H, Sun H, Ji P. How to Deal with Esthetically Overcritical Patients Who Need Complete Dentures: A Case Report. J Contemp Dent Pract 2008 July; (9)5: 22-127.
\end{abstract}

(c) Seer Publishing 


\section{Introduction}

The characteristics of a favorable complete denture include: good biological performance, proper function, and a pleasing appearance. A treatment goal for denture patients is the enhancement of facial appearance. ${ }^{1}$ A substantial number of patients think appearance is even more important than function. ${ }^{2}$ Currently, it is not uncommon for typical denture cases to be considered functionally successful by experts in prosthodontics but are unsatisfactory to the patient. There is also evidence to show patients with emotional problems are more inclined to be dissatisfied with complete denture treatment. ${ }^{3}$ Therefore, the patient subjective evaluation of their denture esthetics is an extremely important consideration in the treatment process by a prosthodontist in order to address patient concern about their personal esthetics in today's social environment. Clinicians need to be sensitive to the psychological needs of their patients in order to achieve an outcome that is completely acceptable. This may require additional training depending on the background of the dentist.

\section{Case Report}

\section{Diagnosis}

A 55-year-old edentulous female presented with a complaint of dissatisfaction with the appearance of two sets of dentures that had been made for her within the previous six months and was seeking a new set of complete dentures. Her specific complaints were as follows:

- The first set of dentures had favorable tooth exposure but did not provide enough lip support (Figure 1).

- On the other hand, the second set provided favorable lip support but too much teeth exposure (Figure 2).

Neither of these conditions was esthetically acceptable to her so she sought another new denture with the same tooth exposure as in the first set but with the same lip support provided by the second set. She consulted a number of dentists who concluded that these treatment goals were "very difficult" or "impossible" to achieve.

Her maxillary residual ridge was the "C" type (Figure 3) with an adequate interarch distance and no temporomandibular disorders.

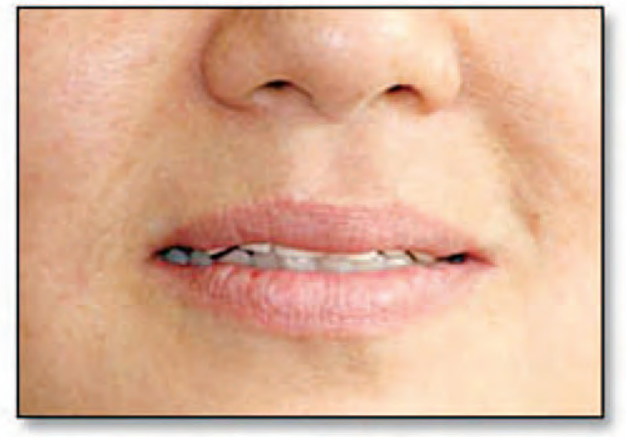

Figure 1. The patient felt this first set of dentures did not provide sufficient lip support.

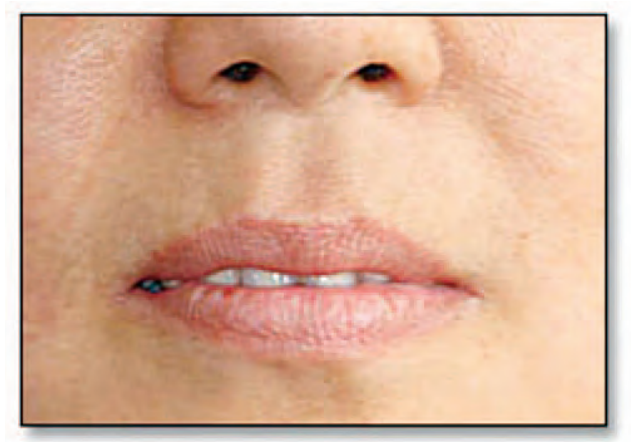

Figure 2. The patient felt there was too much exposure of the maxillary anterior teeth when she smiled with this second set of dentures.

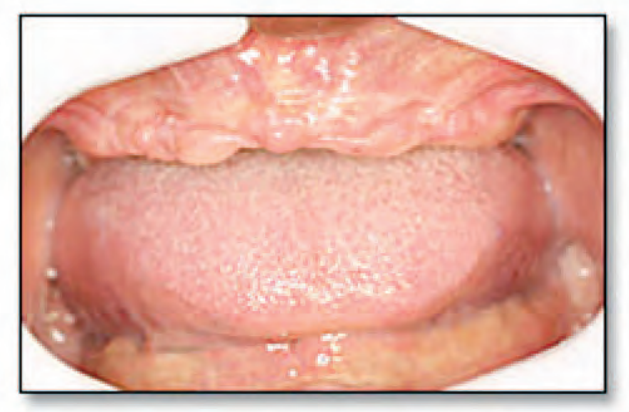

Figure 3. Her maxillary residual ridge was the $\mathrm{C}$ type with adequate interarch distance.

The dental history revealed the patient had focused on evaluating her appearance when her dentist arranged the teeth during the try-in stage for the two previous sets of dentures. She did not give her approval for the dentures to be fabricated until she perceived the arrangement to be perfect. Once the dentures were delivered the patient reevaluated her appearance and became dissatisfied to the extent of finding both sets of dentures completely unacceptable. From 
a prosthodontic perspective the two previous dentures met the standard of care, and it seemed as though the patient was overly critical with regard to esthetics. Since the dentures were adequate, the problem appeared to be psychological and an attempt was made to persuade the patient to accept the previous dentures. This effort failed and the decision was made to make another set of dentures for her.

\section{Treatment}

Treatment was rendered using established medical treatment criteria. This included sufficient communication with the patient especially regarding the esthetic outcome to be expected of the new dentures prior to the onset of treatment. She was informed the final result would largely depend on the extent she was involved in the treatment process as well as her degree of cooperation.

The impression stage was uneventful. However, due to her special psychological state, she was required to be accompanied by either friends or relatives during subsequent visits for denture fabrication and delivery procedures for her new dentures. This strategy served to provide her positive feedback from trusted friends to alleviate her psychologically-based suspicions of a faulty denture even when technical problems with her dentures were non-existent.

The patient used a mirror to evaluate the denture setup and make a judgment about whether the occlusal vertical distance met her esthetic requirements. Approximately an hour was required to achieve patient satisfaction. At that point, the patient was asked to sign the case record to convey her consent to proceed to the next stage of the denture fabrication process.

At the try-in visit, she was accompanied by her husband and a few friends to offer her feedback on her appearance with the denture setup in place. After an hour-long evaluation and discussion process, everyone present agreed the denture setup looked natural and complemented her appearance. At that time, the patient signed the approval for the denture setup in order to proceed to the fabrication of the dentures.

The delivery of the finished denture was the most important moment in the fabrication process. The

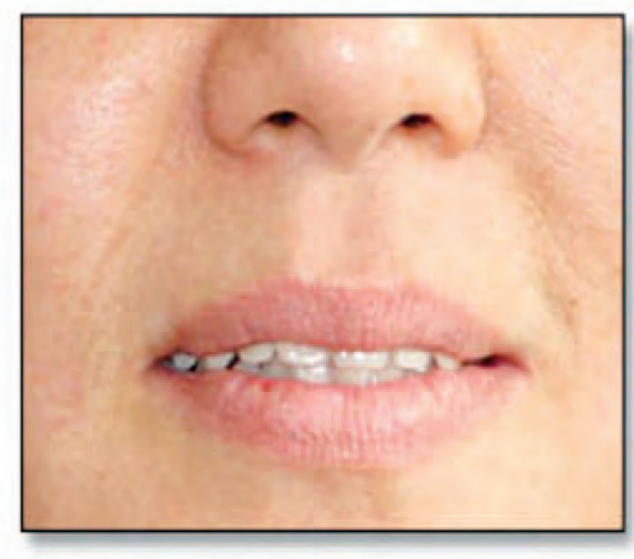

Figure 4. The third set of dentures had the tooth exposure like the first set of dentures and the lip support like the second set when she smiled.

new denture provided the lip support and tooth exposure that appealed to the patient when she smiled (Figure 4). The patient was satisfied with the positive features of her two previous dentures that had been incorporated in this new set of dentures.

No problems were encountered during the postinsertion denture adjustment phase, but before long the patient became overly critical about her appearance again. After a thorough examination, the presence of any technical problem with the denture was ruled out and several psychological strategies were used to achieve patient satisfaction. In addition to the utilization of positive influence from friends and family, a strategy of distracting the patient's attention away from her appearance while focusing on the positive attributes of the denture was employed. This included asking the patient about the following:

- The presence of any discomfort or pain

- The quality of denture retention in terms of whether the denture was inclined to get loose when she chewed or spoke

- The degree of her satisfaction with her chewing efficiency

- Her knowledge of how to maintain and clean the denture

- Her degree of understanding if the proper denture maintenance was carried out would she feel more comfortable when using the denture

Getting the patient to focus on these important issues led to her ultimate acceptance of the new 
denture and the achievement of her satisfaction of the outcome.

\section{Discussion \\ During the fabrication of complete dentures, all factors must be taken into consideration because they can affect the clinician's understanding of the facial esthetics. These factors include the following: \\ - Materials used in the prosthetic restoration \\ - Oral condition of the patient \\ - The dentist-patient relationship \\ - Patient's attitude about the restoration \\ - Patient personality \\ - Socioeconomic situation of the patient \\ - Education level of the patient ${ }^{6,7}$ \\ - Gender of the patient ${ }^{8,9}$}

For psychological reasons, some denture patients are extremely critical of their appearance while wearing dentures despite the lack of fixed standards for esthetics. Such patients are easily influenced by others and can present a patient management challenge for the clinician if not dealt with properly. Past experience suggests attention needs to be paid to the following important patient management fundamentals in the treatment of such patients.

\section{Pre-treatment Communication}

A pre-treatment consultation should include the establishment of esthetic goals. This can be accomplished by clarifying the patient's expectation of the treatment outcome and attainment of a comprehensive understanding of the positive and negative factors that may influence that outcome. ${ }^{10}$ Only by taking all factors described previously into consideration and after the patient fully understands the treatment procedure as well as the advantages and disadvantages of the proposed treatment can a realistic treatment plan be made. Furthermore, those issues, such as the shape, color of the dentures, and arrangements for artificial teeth, etc., which have close relation with the esthetics, shall be decided only after thorough and careful consideration.

\section{Recordkeeping}

Management of an overly critical patient requires the inclusion of a discussion, during the preliminary consultation, of the need for them to approve each step in the clinical aspect of the denture fabrication process. This should be done using written consent to confirm the patient has carefully inspected and are satisfied with each step concerning the esthetic outcome. This provides self-protection for the dentist and serves as a reminder of the patient's participation and approval during the fabrication process should the patient feel dissatisfied with the esthetic outcome of the denture over time. This also serves to effectively improve patient self-confidence about the final appearance of the dentures.

\section{Favorable Clinical Practices}

Treatment procedures must be precise and include the full embodiment of individual care. Impressiontaking, model creation, and the recording of occlusal relationships should be made in compliance within accepted standards of care. The arrangement of the artificial teeth needs to remain consistent with the appearance that existed when the patient tried-in and approved the arrangement of the anterior teeth on the wax occlusal rim at a try-in visit.

\section{Involvement of Friends and Family}

During try-in visits it is advisable for overly critical patients to be accompanied by relatives or friends to provide them feedback on the esthetics of a proposed denture at the wax try-in stage. This is somewhat helpful in terms of improving patient satisfaction when they receive the finished denture. This activity shows the magnitude of the influence of the patient's environment and incorporates a humanistic factor into the patient's subjective evaluation.

\section{Psychological Implications}

Different patients respond to the prospect of becoming edentulous and wearing dentures in different ways. From a psychological aspect, House ${ }^{11}$ classified patients into four types as follows:

- Philosophical mind

- Exacting mind

- Hysterical mind

- Indifferent mind

Exacting-mind patients usually doubt the dentist's ability to make dentures that would satisfy their esthetic and functional needs and demands extraordinary efforts and guarantees of treatment 
outcome at no additional cost. ${ }^{12}$ The behavior of the present patient suggests she might have had an exacting mind set during the process of adapting to dentures. The strategy used to persuade her to accept the elaborate prosthetic denture and appreciate the skills of her dental care providers in the long-term is rather important.

As long as there are no flaws in the denture fabrication process, clinicians can provide patients with more positive information about their prosthesis and guide them toward acceptance and satisfaction with the outcome. Correct application of this psychological approach will yield a significant positive effect on patients who are dissatisfied with their dentures based solely on psychological factors.

The factors not related to dental skills that contribute to the success of denture wearing are becoming more and more important. ${ }^{5}$ Patients must realize the responsibilities they bear in complicated dentist-patient relations. As described previously a favorable outcome for denture patients is founded on good mutual communication, proper understanding, and respect for the patient. It emphasizes the importance of patient involvement during the process of denture fabrication.

\section{References}

1. Steele JG, Ayatollahi SM, Walls AW, Murray JJ. Clinical factors related to reported satisfaction with oral function amongst dentate older adults in England. Community Dent Oral Epidemiol 1997; 25(2):143-9.

2. Elias AC, Sheiham A. The relationship between satisfaction with mouth and number and position of teeth. J Oral Rehabil 1998; 25(9):649-61.

3. Heydecke G, Kkenetti E, Awad MA, Lund JP, Feine JS. Oral and general health-related quality of life with conventional and implant dentures. Community Dent Oral Epidemiol 2003; 16:307-312.

4. Zarb GA, Bolender CL, Carlsson GE. Boucher's prosthodontic treatment for edentulous patients.11th ed. St. Louis: CV Mosby; 1997: 162-181.

5. Sheiham A, Steele JG, Marcenes W, Finch S, Walls AW. The impact of oral health on stated ability to eat certain foods; findings from the National Diet and Nutrition Survey of Older People in Great Britain. Gerodontology. 1999; 16(1):11-20.

6. Kerns LL, Silveira AM, Kerns DG, Regennitter FJ. Esthetic preference of the frontal and profile views of the same smile. J Esthet Dent 1997; 9(2):76-85.

7. Flores-Mir C, Silva E, Barriga M, Lagravere MO, Major PW. Lay person's perception of smile esthetics in dental and facial views. J Orthod 2004; 31(3):204-9.

8. Tickle M, Kay EJ, Bearn D. Socio-economic status and orthodontic treatment need. Community Dent Oral Epidemiol 1999; 27(6):413-8.

9. Chia RC, Allred LJ, Grossnickle WF, Lee GW. Effects of attractiveness and gender on the perception of achievement-related variables. J Soc Psychol 1998; 138(4):471-7.

10. Mazurat NM, Mazurat RD. Discuss Before Fabricating: Communicating the Realities of Partial Denture Therapy. Part I: Patient Expectations J Can Dent Assoc 2003; 69(2):90-4.

11. House MM. Full denture technique. In: Conley FJ, Dunn AL, Quesnell AJ, Rogers RM, editors. Classic prosthodontic articles: a collector's item. Vol III. Chicago: American College of Prosthodontists; 1978. p. 2-24.

12. Gamer S, Tuch R, Garcia LT. M. M. House mental classification revisited: Intersection of particular patient types and particular dentist's needs. J Prosthet Dent. 2003; 89(3):297-302. 


\section{Hulfen Ma, BDs, MDS}

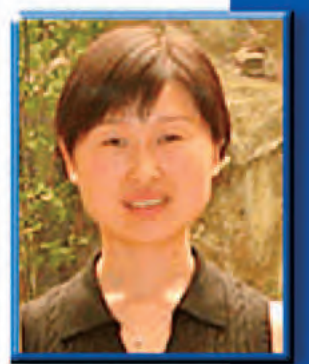

Dr. Ma is a graduate student in the Department of Prosthodontics of the College of Stomatology at Shandong University in Jinan Clty, Shandong Province, China where she recelved her BS in 2005 and will recelve her Masters degree in June 2008.

e-mall: mahulfen21@126.com

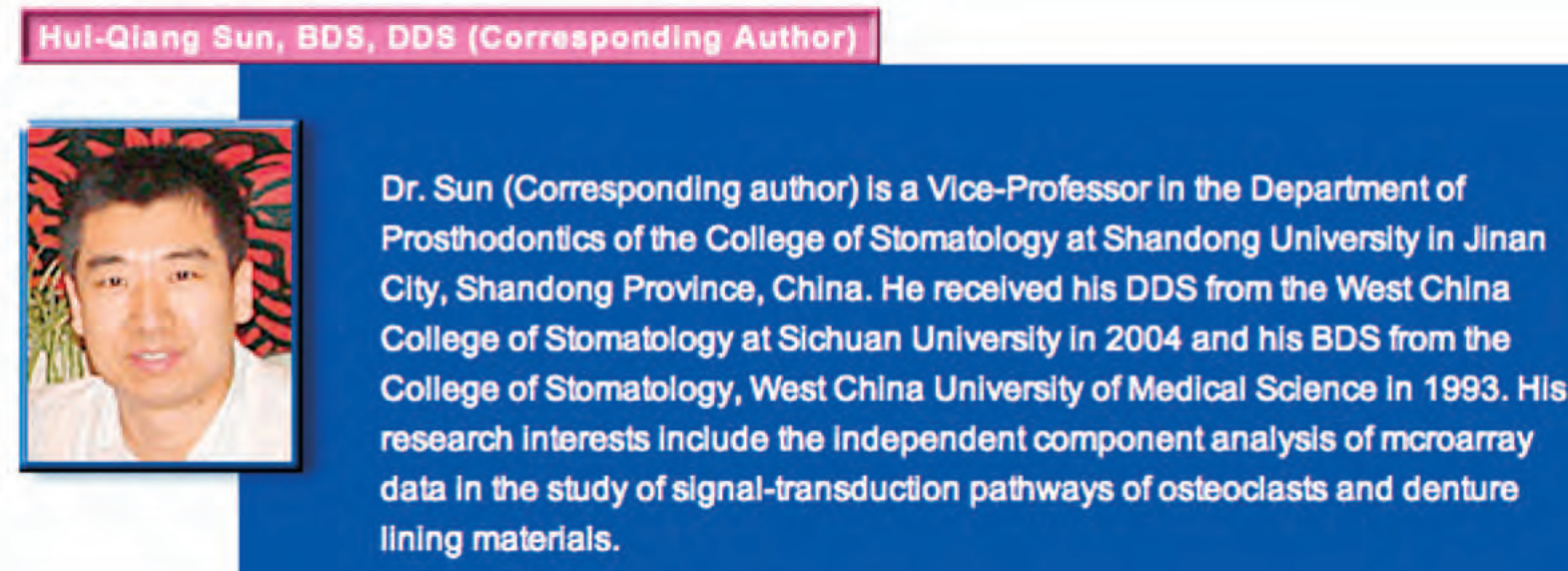

e-mall: whltedove69@163.com

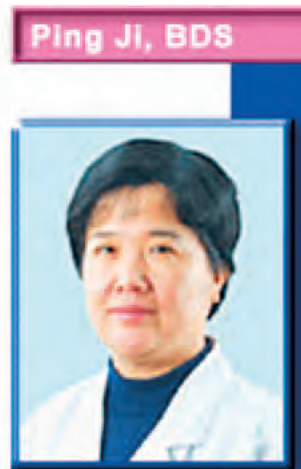

Dr. Jl is a Professor in the Department of Prosthodontics of the College of Stomatology at Shandong University in Jinan City, Shandong Province, China. She recelved her BDS from Shandong University in 1982.

e-mall: Liping@sdu.edu.cn 